
estudantis contra os cortes na educação nas cidade de Goiânia e Londrina 15 de maio 2019. Domínios da imagem, v. 13, n. 25, p. 133-157, jul./dez. 2019.

Recebido em 02/06/2019 e aprovado em: 15/10/2019

\title{
IMAGENS FOTOGRÁFICAS SOBRE AUTORITARISMO E MANIFESTAÇÕES ESTUDANTIS CONTRA OS CORTES NA EDUCAÇÃO NAS CIDADES DE GOIANIA E LONDRINA 15 MAIO 2019
}

\author{
PHOTOGRAPHIC IMAGES ABOUT AUTHORITY AND \\ STUDENT MANIFESTATIONS AGAINST CUTS IN EDUCATION \\ IN CITIES OF GOIANIA AND LONRINA 15 MAY 2019
}

Gledson Rodrigues Nascimento•

\begin{abstract}
Resumo: Neste texto procuramos construir, por meio de imagens fotográficas, parte do que aconteceu nas manifestações estudantis, ocorridas em 15 de maio 2019, em várias cidades brasileiras, contra o corte nos recursos da educação. Pensamos que esse episódio se assemelha com ocorrido no "Maio de 68", em Paris, por isso aglutinamos alguns fatos e imagens que ajudaram na sua reverberação pelo Brasil, ainda em 1968. A finalidade é mostrar como a posição estudantil influencia o comportamento revolucionário e transgressor dos que lutam por mudanças, sempre que a intenção de favorecer a massa, com sonhos revolucionários, torna-se um ideal, para promover direitos aos estudantes e à sociedade. Metodologicamente, utilizaremos recursos como, netnografia, etnografia virtual e os acervos digitais on-line, além das contribuições de Dubois (2004). Considerando os atos de focar, enquadrar e acionar o dispositivo de recorte de espaço e tempo, para mostrar como foram as manifestações nas cidades de Goiânia-GO e Londrina-PR, no dia 15 de maio de 2019.
\end{abstract}

Palavras Chave: Imagens Fotográficas. Maio de 68. Manifestações Estudantis15 de Maio de 2019. Netnografia.

Abstract: In this text, we seek to build, through photographic images, part of what happened in the student manifestation, which took place on May 15 , 2019, in several Brazilian cities, against the cut in education resources. We think that this fact resembles what happened on the "May 68" in Paris, so we gathered some facts and images that helped in its reverberation in Brazil, still in 1968. The purpose is to show how the student position influences revolutionary and transgressor behavior of those who fight for change, whenever the intention of favoring the masses with revolutionary dreams becomes an ideal to promote rights for students and society. Methodologically, we will use resources such as netnography, virtual ethnography, and online digital collections, in addition to the contributions of Dubois (2004). Considering the

\footnotetext{
- Mestre em Arte e Cultura Visual, pela Universidade Federal de Goiás - UFG - Goiânia - GO Doutorando em Teoria e História da Arquitetura e Urbanismo, Universidade Nacional de Brasília - UNB, DF. E-mail: gledson-rn@hotmail.com.
} 

estudantis contra os cortes na educação nas cidade de Goiânia e Londrina 15 de maio 2019. Domínios da imagem, v. 13, n. 25, p. 133-157, jul./dez. 2019.

acts of focusing, framing and triggering the space and time clipping device, to show how the demonstrations were in the cities of Goiânia-GO and Londrina-PR, on May 15, 2019.

Keywords: Photographic Images; May 68; Student Manifestations- May 15 2019; Netnography.

\section{Imagens e relatos sobre o autoritarismo do maio de 1968 em Paris e sua reverberação no Brasil}

A repercussão das manifestações estudantis, ocorridas em maio de 68, em Paris, ecoou por outros continentes. Iniciada no interior da faculdade francesa de Nanterre, esse episódio relata como os estudantes se posicionaram contra a maneira de produção do conhecimento, imposta pelo governo frances. Essa imposição, seguia uma caracterizção de padrões industriais, com interesses centrados no liberalismo, ao rigor dos modelos de autogestão. Para enfatizar tais ocorrências, utilizamos o potencial imagético que há nas imagens, sobretudo nas imagens fotográficas, a partir do que descreve Ulpiano Meneses.

As imagens carregam em si mesmas eternidade e
transcendência e estão abertas para o mundo e para o novo.
Ao se aproximar do campo visual, o historiador reteve quase
sempre, exclusivamente a imagem - transformada em fonte de
informação. Conviria começar, portanto, com indagações
sobre a percepção do potencial cognitivo da imagem para
compreendermos como ela tem sido explorada, não só pela
história, mas pelas demais ciências sociais, e, antes disso, no
próprio interior da vida social, na tradição do ocidente
(MENESES, 2003, p. 12).

As informações que as imagens carregam, transcendem em uma abertura de referências para o mundo, sobretudo com narrativas e relata a postura dos estudantes em Paris. Mesmo antes de enfrentarem a polícia, por determinados locais centrais da cidade, em campo aberto. Contudo, no acontecimento desse episódio, ocorrido em plena Boulevard Saint-Germain, é possível observar na imagem 01, onde e como os estudantes se acomodaram, antes de decidirem pelo embate. 
NASCIMENTO, Gledson Rodrigues. Imagens fotográficas sobre autoritarismo e manifestações estudantis contra os cortes na educação nas cidade de Goiânia e Londrina 15 de maio 2019.

Domínios da imagem, v. 13, n. 25, p. 133-157, jul./dez. 2019.

A referida imagem, retrata também as condições em que se encontravam esses estutdantes no interior de uma arquitetura, voltada para algo como as assembleias e convenções. O local mostrado, trata-se do interior do Anfiteatro Richelieu, que abrigou os manifestantes de fomra improsvisada. Assim como mostra a imagem 01, dormiam nos bancos da sala de aula magna da Sorbonne. Essa cena, foi registrada semanas antes de iniciarem as manifestações conhecidas como a "primavera parisiense em maio de 68".

No momente desse recorte de espaço e tempo, eles debatem sobre as medidas autoritárias impostas pelo governo, antes de se organizarem para o confronto.

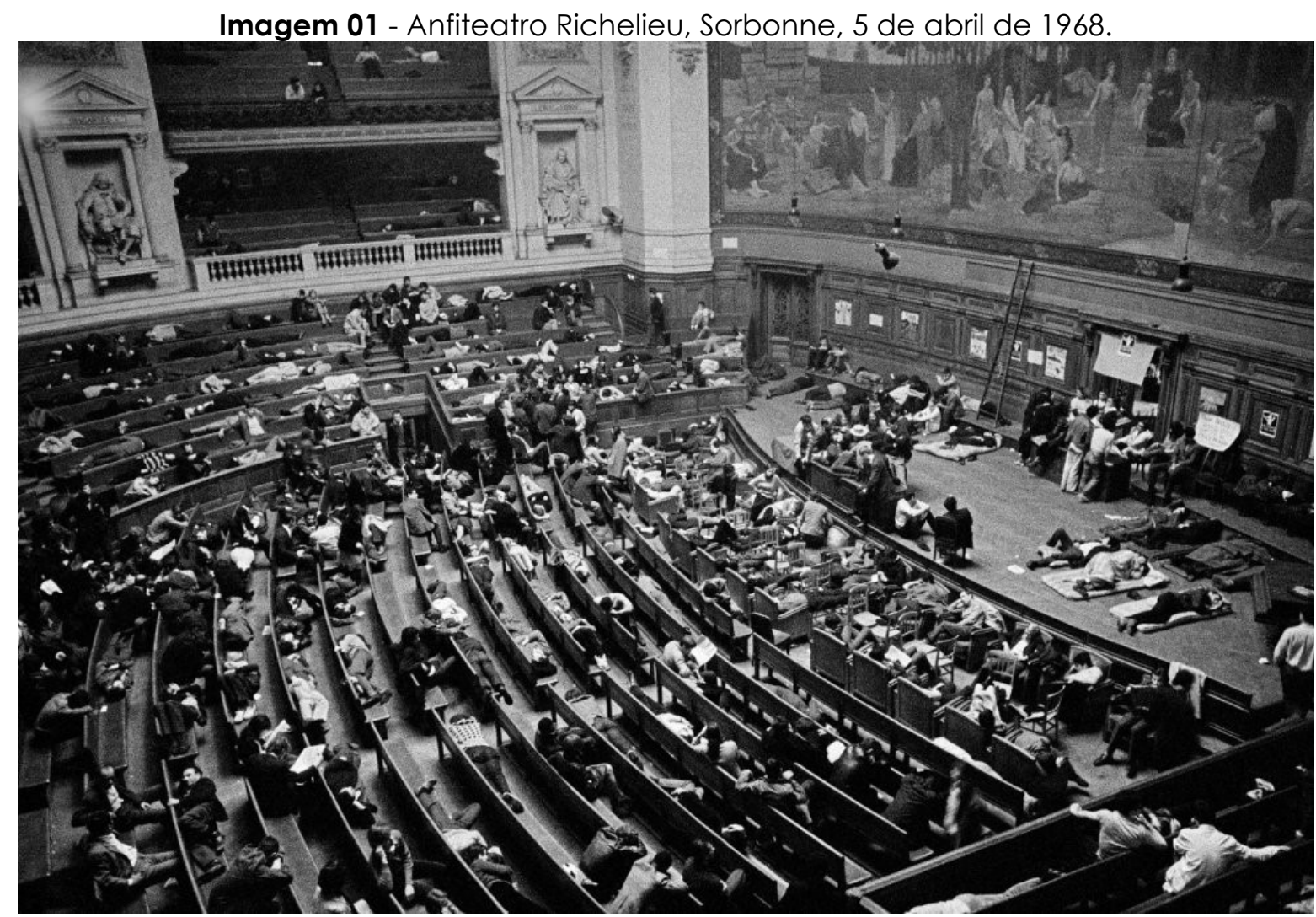

Fonte:https://brasil.elpais.com/brasil/2018/04/18/album/1524051270 015115.html\#foto gal 11

Autor: Bruno Barbey 

estudantis contra os cortes na educação nas cidade de Goiânia e Londrina 15 de maio 2019.

Domínios da imagem, v. 13, n. 25, p. 133-157, jul./dez. 2019.

Desse modo, mesmo com indagações que também atravessam o potencial cognitivo, a imagem 01 torna-se fonte de informação histórica e enfatiza um capítulo da história. Marcado pela resistência e insurgências por parte dos estudantes, que eram contra as transformações propostas pelo governo francês, para a educação. Apesar das manifestações ainda não haverem estourado, a imagem 01 mostra, como os estudantes já se preparavam, desde o mês de abril do mesmo ano. Alojados de forma improvisada, reuniram, debateram e organizaram as ações contra a posição autoritária do governo que tinha a intenção de atender aos interesses típicos da sociedade de consumo, surgida nos anos 60. Tais interesses se dariam, por meio da imposição de um modelo de sistema econômico que ameaçava a qualidade do sistema de ensino do pais. Isso, os estudantes não iriam permitir.

Nesse sentido, a posição dos estudantes, seguia um pensamento já registrado por Eric Hobsbawm (1995), que denominou a década de 60, como os "anos de ouro", e seguido do fim da Segunda Guerra Mundial, foi marcado por uma grande expansão econômica global. Hobsbawm, ainda relata que a "A economia mundial crescia a taxas explosivas e que jamais houvera algo assim. Onde a produção mundial de manufaturas quadriplicou entre início da década de 1950 e o início da década de 1970, e, o que é mais impressionante, o comércio mundial de produtos manufaturados, aumentou dez vezes" (HOBSBAWM, 1995, p. 257).

Consequentemente, a posição dos estudantes franceses era contraria ao alinhamento do governo francês ao sistema econômico imposto, pelos motivos descritos por Hobsbawm (1995). Pois, não só comprometia a qualidade do ensino, como também desconstruíria o modelo educacional, em vigor. Logo os estudantes entenderam que desse modo, ameaçaria a produção do conhecimento. Contudo, foi essa posição arbitrária do governo que causou revolta entre a comunidade estudantil, e após alguns embates, eles deram início a uma série de manifestações. Algumas sob batalhas violentas contra forças políciais, pelas ruas centrais da capital francesa. 
NASCIMENTO, Gledson Rodrigues. Imagens fotográficas sobre autoritarismo e manifestações estudantis contra os cortes na educação nas cidade de Goiânia e Londrina 15 de maio 2019.

Domínios da imagem, v. 13, n. 25, p. 133-157, jul./dez. 2019.

Esse posicionamento da comunidade estudantil, é descrito por Alain Touraine (1970), que não se tratava somente de uma maneira de tomar o poder político, naquele momento mas sim de destruí-lo completamente. Conforme relata Touraine, o objetivo dos estudantes era eliminar tudo que representasse qualquer ameaça a organização administrativa e institucional, relacionado a educação. Assim, a comunidade estudantil mostrou sua reação, contra um modelo de sistema econômico, ancorado ao crescimento da economia mundial e atrelado a uma expansão industrial, de certo modo nociva. Pois com os seus propósitos de atender aos interesses típicos de uma sociedade de consumo, comprometeria o sistema de ensino do país.

Sobre essa posição da comunidade estudantil francesa, a imagem 02 evidencia um momento em que os manifestantes, entram em conflito com as forças policiais de repressão. Incidando então, os atos de manifestações pelas ruas centrais da capital francesa que ecoarm pelo mundo.

Imagem 02 - Manifestantes enfrentam a polícia na Boulevard Saint-Germain, em maio de

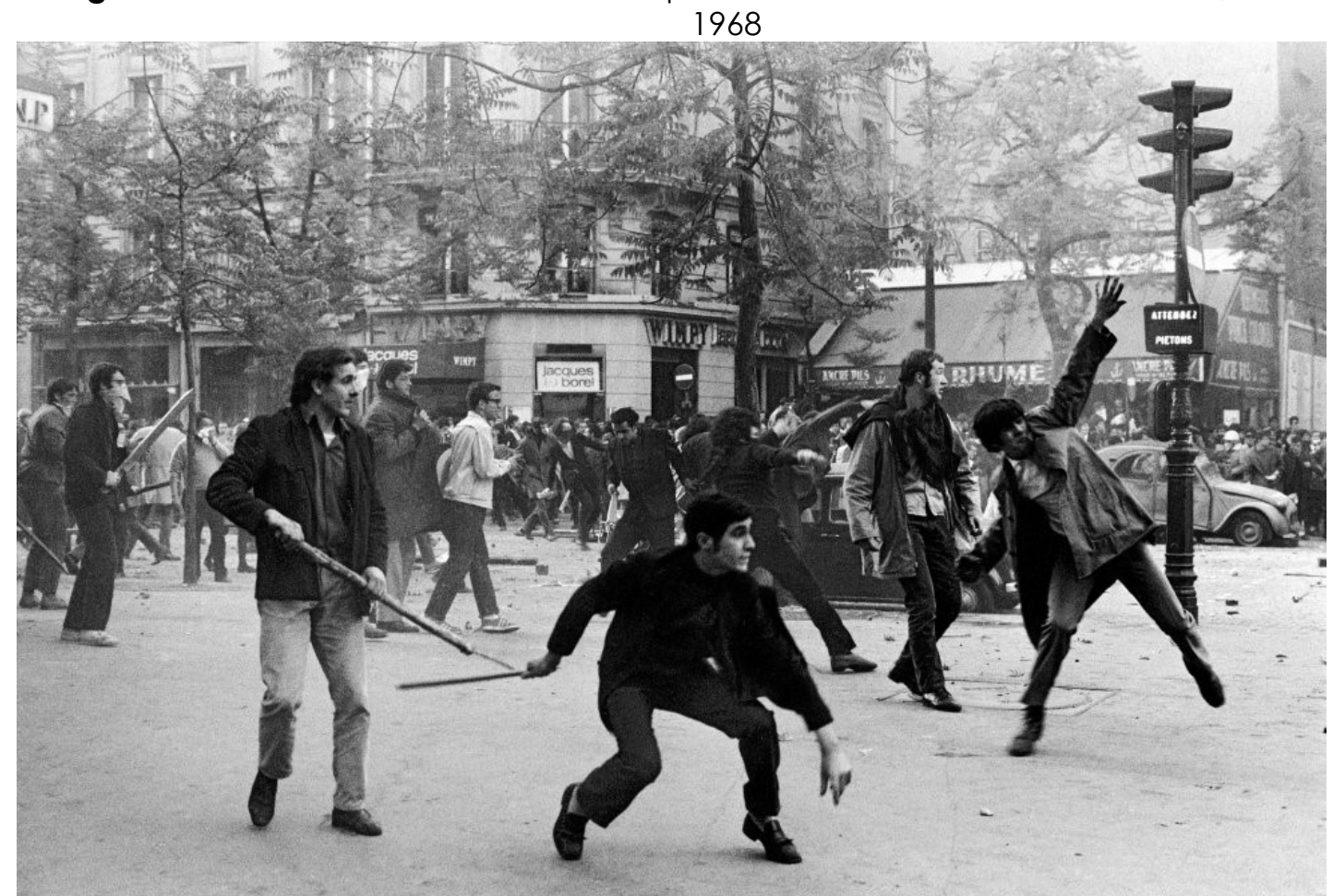

Fonte:https://brasil.elpais.com/brasil/2018/04/18/album/1524051270_015115.html\#foto_gal 11

Autor: Bruno Barbey 

estudantis contra os cortes na educação nas cidade de Goiânia e Londrina 15 de maio 2019.

Domínios da imagem, v. 13, n. 25, p. 133-157, jul./dez. 2019.

Conforme mostra a imagem 02 , os manifestantes contra-atacam as forças policiais, com paus, pedras, barras, projéteis de aço, e o que mais encontravam pela frente. Assim foi o embate ocorrido na Boulevard SaintGermain, muito próximo ao bar La Rhumerie. Segundo o jornal El Pais, esse bar que também pode ser conferido junto à imagem 02, foi uma outra arquitetura que marcou essa página da história. Logo é possível de ser identificado diante do trânsito do olhar pela imagem, mais ao fundo, onde há um toldo com seu nome, meio apagdo, segundo o referido jornal, também foi ponto de reuniões e encontros dos estudantes franceses, no maio de 68.

De toda forma, esse habitual trânsito do olhar pela imagem, busca, mapeia e às vezes identifica o que o texto descreve. Portanto a expressão dos corpos de alguns estudantes, dos fotógrafos, e os estilhaços espalhados pelo chão, também mostram o que foi esse episódio. E em meio a todo esse cenário de confrontos, Touraine (1970) afirma que o "maio de 68" foi um dos primeiros conflitos urbanos de classes, que se instalou nas sociedades capitalistas avançadas. "E junto com os grandes movimentos, mais dramáticos dos países socialistas, inseriu um manifesto que deu origem a um novo período da história social das sociedades industriais" (TOURAINE, 1970, p. $53)$.

Neste sentido Touraine (1970) traz à tona o embate entre os que representavam as lutas de classe e a posição de uma classe burguesa que seguia os moldes de uma sociedade de consumo atenta a produção do capitalismo industrial, que avançava sobre outros territórios. Em todo esse cenário de diferenças, para os industriais desse período, toda essa ameaçadora transformação econômica, teria que ter seguimento. Para isso, não deveriam se importar com o que comprometeria, o futuro de uma geração de pessoas, uma vez s os industrais se interessavam somente com as taxas explosivas de crescimento economico, decorrentes do modelo de economia mundial, da época. 

estudantis contra os cortes na educação nas cidade de Goiânia e Londrina 15 de maio 2019. Domínios da imagem, v. 13, n. 25, p. 133-157, jul./dez. 2019.

Portanto, essa espécie de nova ordem mundial, que implicava em mudanças por meio de um sistema econômico pretencioso, com consequências prejudiciais a qualidade do ensino, os estudantes parisienses não permitiriam que ocorresse de forma pacífica.

\section{A repercussão do maio de 1968 e a ditadura militar no Brasil}

As manifestações do maio parisiense de 68, que recentemente completaram 50 anos, ecoaram pelo mundo, e chegando ao Brasil em um momento de enfrentamento dos estudantes à uma conjuntura política brasileira perversa. Nesse período as entidades estudantis brasileiras já haviam se rebelado, por meio de diversos atos, contra o autoritarismo e a repressão, impostas desde o Golpe de 1964.

Mesmo com toda a repressão já operando, os estudantes lutavam por meio dos seus sonhos revolucionários, defendendo a liberdade de expressão e os direitos humanos, com ideais contrários aos do regime militar ditatorial. Entre outras arbitrariedades, esse regime retirou à força o presidente João Goulart do poder, apoiado por diferentes frentes conservadoras e simpatizantes ao propósito de repressão militar, imposto desde 1964, inclusive com representantes da sociedade. Conforme descreve Santana (2007), o golpe, que depôs Jango, recebeu apoio de representantes da

Marcha da família com Deus pela liberdade, organizada pela Igreja Católica e pelo empresariado, disseminando uma campanha anticomunista, com ampla adesão da classe média e de setores importantes dos trabalhadores rurais e urbanos (SANTANA, 2007, p. 41).

De toda forma, parcelas organizadas da sociedade, envolvenda parte da classe média, da igreja e de alguns empresários, alinharam com os propósitos do Golpe de 64. Contudo, os estudantes não perderam os seus ideais e continuaram suas ações contra o regime, também em embates pelas 

estudantis contra os cortes na educação nas cidade de Goiânia e Londrina 15 de maio 2019. Domínios da imagem, v. 13, n. 25, p. 133-157, jul./dez. 2019.

ruas, conforme pode ser conferido pela imagem 03. Ela retrata como aconteceram as várias manifestações, inclusive as que ocorreram em dezembro de 1968.

E como se não fosse o bastante, toda essa estrutura organizada da sociedade envolvendo, igreja, a marcha da família, empresários, assim como parte da classe média, estiveram à favor da repressão violenta do regime militar contra os que combatiam sua postura autoritária. Incluindo também, até alguns setores importantes dos trabalhadores ruais e urbanos. E para completar ainda mais toda a força repressora do regime, em dezembro de 1968, foi decretado Ato Institucional número cinco, (Al-5). O Al-5, pode ser compreendido como uma resposta do governo golpista, por meio de medidas mais duras e repressoras contra os que se manifestaram, contrários ao regime militar de 1964. A imagem 03 enfatiza um dos vários dias de enfrentamento dos estudantes, contra as forças policiais de repressão, em junho de 1968, meses antes de ser baixado o Al-5.

Imagem 03 - Policiais reprimem estudantes em junho de 1968 - Arquivo O Globo

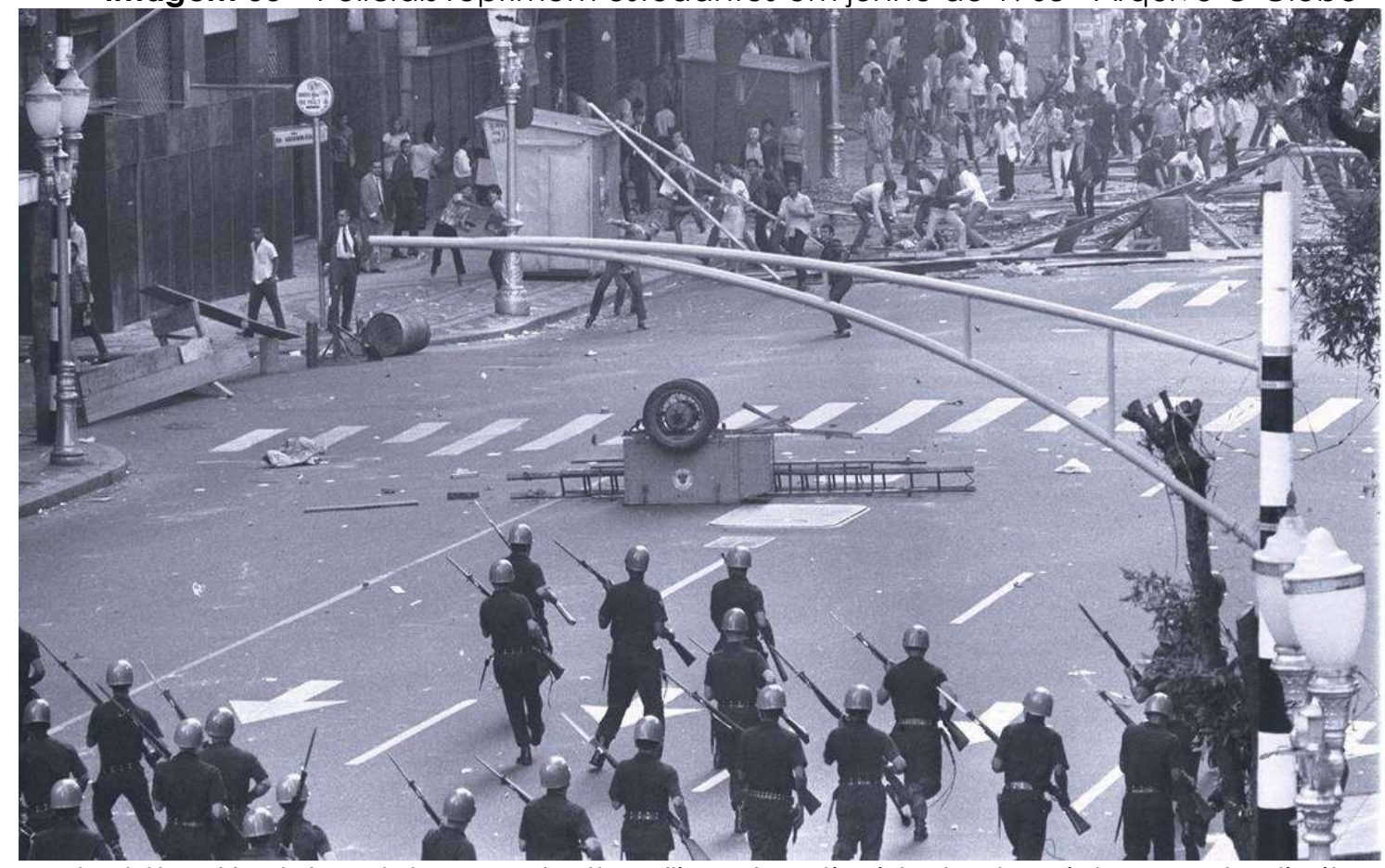

Fonte: https://oglobo.globo.com/cultura/livros/continuidade-das-violacoes-de-direitoshumanos

Autor: O Globo 

estudantis contra os cortes na educação nas cidade de Goiânia e Londrina 15 de maio 2019.

Domínios da imagem, v. 13, n. 25, p. 133-157, jul./dez. 2019.

Extraída de uma versão on-line dos arquivos do jornal o Globo, a imagem 03, retrata parte do que foram os embates entre as forças de repressão contra os atos de manifestações em algumas cidades brasileiras. Na referida imagem, consta uma distância entre ambos os lados do embate e mostram os policiais com armas letais, reprimindo os manifestantes que pegavam o que encontravam pela frente, para se defender e também contra-atacar.

Sendo assim, a imagem foto narra também, como foram os embates em solo brasileiro, representando bem o período de repressão, contra a liberdade de expressão no Brasil entre os anos de 1964 e 1968. Contudo, o Ato Institucional número 5, ao estabelecer medidas ainda mais radicais, das que já ocorria, conforme descreve Santana (2007, p. 42), "a repressão agia no âmbito educacional. E do mesmo modo, agia também na sociedade, perseguindo aqueles que consideravam subversivos, tratando todos como suspeitos até que se provasse o contrário".

Essa medida radical, fez com que agentes em nome de um governo ditatorial, perseguissem e prendessem diversas pessoas, algumas passaram por sessões de tortura, outras desapareceram e foram assassinadas. As vítimas desse sistema, eram em sua grande maioria jovens estudantes, tanto universitários quanto secundarístas que e para serem perseguidos, bastava participar de passeatas e manifestações contra o governo.

O golpe de 64, o maio de 1968 e o Al-5, reverberaram sobre as cidades que desenvolveram atividades classificadas como subversivas. Na cidade de Goiânia, não foi diferente para os estudantes que lutavam pela democracia e contra as ações brutais do regime. Os agentes de repressão atuaram de forma dura, em vários locais, considerados palco de manifestações, "alguns deles ocorreram nas portas das universidades, próximo à praça universitária" descreve professor Pantaleão (2018). Ele também relata 
NASCIMENTO, Gledson Rodrigues. Imagens fotográficas sobre autoritarismo e manifestações estudantis contra os cortes na educação nas cidade de Goiânia e Londrina 15 de maio 2019. Domínios da imagem, v. 13, n. 25, p. 133-157, jul./dez. 2019.

sobre casos de prisões e até de desaparecimento de jovens militantes, na cidade de Goiânia, após atos de manifestações, ressalta o professor1.

\section{Produção de pesquisa com imagens fotografias, netnografia e seus desdobramentos}

A pesquisa com imagens sobre atos políicos ocorridos em espaços públicos, nesse caso, se deu por metodologias deferentes. Além da fotografia e das caminhadas exploratórias, foi utilizado também outro recursso de observação interessante, chamado netnográfica ${ }^{2}$. Portanto, o recursos netnográficos, vem dando suporte a outros campos de estudos culturais, entre eles, estão a antropologia visual, a história da arte, a sociologia, a filosofia, entre outros. De toda forma, tem dado suas contribuições também as pesquisas que o campo de estudos sobre Cultura Visual vem se desenvolvendo. Desse modo, para produzir pesquisas com imagens, em um contexto cultural e imagético, deve-se considerar as fontes visuais produzidas por alguns lugares dos centros urbanos das cidades. Pois em alguns desses lugares, a Arquitetura e o Urbanismo compõem as imagens, juntamente com as dinâmicas sociais, decorrentes de "ações políticas em espaços públicos"3. Logo, independentemente do recorte espacial e temporal, o fato de reallizar pesquisa envolvendo imagens fotográficas, faz desencadear construções de sentidos sobre o que dizem as imagens. Assim como o que elas registraram sobre as manifestações, fazendo emergir construção de entendimentos registrados pela prática de fotografar, como o que se verificou nas cidades de Goiânia e Londrina.

\footnotetext{
1 Professor de Historia, aposentado e militante político desde os anos 60.

2 O termo netnografia é uma combinação das palavras net e ethnography e foi cunhado pelos pesquisadores norte-americanos Bishop, Star, Neumann, Ignacio, Sadunsky e Schatz em 1995 com o objetivo de descrever o desafio metodológico de preservar os detalhes da observação em campo etnográfico usando o meio eletrônico para acompanhar os indivíduos CORRÊA, ROZADOS (2017, p.3).

${ }^{3}$ RIFA-VALLS, M. Processos de fabricação visual do protesto no espaço público através de Hanna Arendt. Set. 2018.
} 

estudantis contra os cortes na educação nas cidade de Goiânia e Londrina 15 de maio 2019. Domínios da imagem, v. 13, n. 25, p. 133-157, jul./dez. 2019.

Essa verificação entre as duas cidades em referência, ocorrida por meio de experiências visuais sobre manifestações políticas em espaços públicos, foi resultado do objetivo de participar mais uma vez do ENEIMAGEM e EIEIMAGEM. Então entre os dias 14 a 17 de maio de 2019, me desloco para a cidade de Londrina, com a finalidade de apresentar como comunicador de tabalhos científicos, parte do que tenho pesquisado sobre imagens da arquitetura colonial na Cidade de Goiás. Além do trabalho de comunicação, envolvendo fontes visuas sobre arquitetura colonial, inscrito no eixo temático 5 - Espaço paisagem e construção, como os demais, também participei de um minicurso4 com o tema: "A construção da imagem documental: narrativas fotográficas", essa segunda atividade foir dividida em três momentos. O primeiro ocorrev em sala de aula, com a apresentação de slides sobre o tema proposto, envolvendo paisagens e memória, sempre permeado de imagens fotográficas, foi abordado a todo momento temáticas com os sujeitos produtores de pesquisa. Contudo, temas como cartografias e autores como Deleuze, Guatarri e Carlos Rodrigues Brandão, foram apresentados, à partir do comportamento e das práticas de pesquisadores, com e sobre autores, dentro de suas próprias pesquisas.

Nessa experiência, inferiu-se que os agentes produtores de pesquisas, sobretudo com imagens, estão atentos a tudo, no momento de contato com o lugar observado.

\footnotetext{
${ }^{4}$ Ministrado por André Camargo Lopes - Dr. em História e Sociedade -UNESP, Ms. em História Social - UEL. É professor da Rede Estadual de Ensino, Estado do Paraná. Trabalha com estudos culturais e cultura visual. Pesquisa temas como: religiosidade popular, fotografia e iconografia vernacular, arte e ensino de arte.
} 

estudantis contra os cortes na educação nas cidade de Goiânia e Londrina 15 de maio 2019.

Domínios da imagem, v. 13, n. 25, p. 133-157, jul./dez. 2019.

Logo em seguida, sob uma atividade com o tema, "Construindo uma narrativa sobre o espaço", todos participantes do referido minicurso foram divididos em grupos temáticos, com a finalidade de desenvolver uma "Ação exploratória". Essa ação, compreenderia o segundo momento do minicurso e consistia em fotografar com as câmeras dos celulares dos participantes, o que fosse observado durante uma "caminhada exploratória", ao longo da Rua Sergipe no centro da cidade de Londrina.

No entanto, cada participante com o seu referido tema, realizou sob o trânsido do olhar e seus respectivos dispositivos, imagens fotográficas, para posteriormente apresentá-las, em um terceiro momento. Encerrando assim o minicurso com as respectivas construções de narrativas por meio de imagens, realizadas durante as caminhadas exploratórias e "observação direta". Sobre essa maneira de observação Rocha e Eckert (2008) descrevem que,

A observação direta é sem dúvida a técnica privilegiada para investigar os saberes e as práticas na vida social e reconhecer as ações e as representações coletivas na vida humana. É se engajar em uma experiência de percepção de contrastes sociais, culturais e históricos. As primeiras inserções no universo de pesquisa conhecidas como "saídas exploratórias", são norteadas pelo olhar atento ao contexto e a tudo que acontece no espaço observado. (ROCHA; ECKERT, 2008, p.2)

A experiência dessa maneira de observação, descrita por Rocha e Eckert (2008), permite tecer indagações sobre a realidade do lugar, antes e durante $o$ ato de fotografar. Com esse contato inicialmente visual, tornou-se possível abrir outras maneiras de captar e entender sobre informações inesperadas, pelo trajeto percorrido, em certas localidades da cidade e sobre os objetos observados,

Essa vivência mostrou que é possível construir, a partir de noções sobre historiografia, antropologia visual, e também sobre um patrimônio histórico material e imaterial, que as inquirições ocorridas, vão consubstanciando os motivos dos enquadramentos fotográficos. Pois em meio 

estudantis contra os cortes na educação nas cidade de Goiânia e Londrina 15 de maio 2019. Domínios da imagem, v. 13, n. 25, p. 133-157, jul./dez. 2019.

a arquitetura das cidades, vão se revelando, compreensões, culturais expecíficas do centro da cidadde de Londrina. As questãos políticas e sociais também emergem desta analogia, que operam em lugares específicos das regiões centrais urbanas, consideradas como locais de visibilidade para monifestações e atos políticos.

Portanto, o sujeito produtor de pesquisa, ao relizar o "ato fotográfico", faz da fotografia, algo que vai além de uma metodologia, e pode ser entendida como "um instrumento de uma memória documental do real" (Dubois, 2004, p.29). Esse real do qual descreve Dubois (2004), se manifesta a todo tempo de uma forma viva e mutável. Perpassa entre os percursos trilhados, durante as práticas de pesquisas e produção de fontes visuais, levando em conta à produção de sentidos e construção de entendimentos promovida pelas imagens fotográficas. Nesse sentido, podemos inferir que as narrativas visuais, decorrentes da pratica de pesquisar com imagens fotográficas, produzem resultados imagéticos, intrínsecas ao comportamento da sociedade, e de suas mais variadas atividades. Desse modo, as narrativas visuais, podem emergir de fotografias produzidas em espaços urbanos, como ocorreu no Maio de 68, assim como nas oficinas, e nos trabalhos de comunicação do ENEIMAGEM e EIEIMAGEM, em maio de 2019. Considerando que independentemente do seu recorte espacial ou temporal, em ambos os casos, envolvendo, espaço, tempo e manifestações políticas, há um olhar ávido por informações, sobretudo visuais. Contudo são essas informações sentidas e registradas, sobre o olhar atento do pesquisador, quando e "enquanto programa de investigação: a natureza construída do olhar e das formas de expressão e comunicação visual" (CAMPOS, 2012, p.20), carregam em sim uma infinidade de interpretações, quando observadas em cada um dos seus planos. Nesses planos, são revelados a cada investigação, representações de motivações políticas, econômicos e sociais em constante manifestação. 

estudantis contra os cortes na educação nas cidade de Goiânia e Londrina 15 de maio 2019. Domínios da imagem, v. 13, n. 25, p. 133-157, jul./dez. 2019.

Entre as dimensões visuas apresentadas pelos planos das imagens produzidas, como nas referidas manifestaões sociais, "enquanto [...] natureza construída do olhar [...]", há também sensações que as imagens não conseguem captar e reproduzir, quando comparado aos olhos de quem as observa, e captam o recorte de espaço e tempo. Pois para vivenciar as sensações que as imagnes por vezes não conseguem captar, é preciso caminhar, explorando e fotografando por entre os objetos observados. Pois é em contato com o território dos objetos pesquisados que vivencia-se as experiências sensitivas, e motivadoras do ato de fotografar. Mesmo quando se esta em trânsito, como no caso em questão, envolvendo duas cidades relativamente distantes. Mesmo se tratanto de experiências, e de produção de fotografias sobre manifestações em espaço público urbano, de cidades diferentes ao mesmo tempo.

\section{Experiências fotográficas sobre manifestações do 15 de maio de 2019 em Goiânia}

Essa distância geográfica entre Londrina e Goiânia, não impediu que as manifestações ocorridas em 15 de maio de 2019 fossem divulgadas quase em tempo real, tanto pelas redes sociais, via aplicativos de celular, quanto pela internet acessada por computadores. Logo se entende que esse recurso de informações, sobretudo visuais, permitido graças à internet, conhecido como netnografia, é descrito por (Kozinets apud Corrêa, Rozados, 2017) da sequinte forma:

[...] netnografia - um método de pesquisa, baseado na observação participante e no trabalho de campo online, que utiliza as diferentes formas de comunicação mediada por computador como fonte de dados para a compreensão e a representação etnográfica dos fenômenos culturais e comunais. O método netnográfico começou a ser desenvolvido nos anos 90 no campo da pesquisa de marketing e de consumo, uma área interdisciplinar que se caracteriza por incorporar pontos de vista de diversos campos, como a antropologia, a sociologia e os estudos culturais (KOZINETS Apud CORRÊA, ROZADOS, 2017,p.3). 

estudantis contra os cortes na educação nas cidade de Goiânia e Londrina 15 de maio 2019. Domínios da imagem, v. 13, n. 25, p. 133-157, jul./dez. 2019.

A partir do que descreve Corrêa e Rozados(2017) sobre netngrafia, como prática de pesquisa, e também como um tipo de metodologia, foi possível construir entendimentos sobre as manifestações que ocorreram em diversas cidades brasileiras, no dia 15 de maio de 2019. Essa contrução de entendimento se fez por meio de produção de imagens que preencheram as páginas de alguns sites e também de matérias produzidas para acervos digitais, on-line. Todo esse cenário imagético e netnográfico, também cobriu a cidade de Goiânia em 15 de maio de 2019, para o mundo, assim como ocorreu em outras cidades brasileiras. Esse cenário também revelou as ruas centrais dessa e de outras capitais ocupada por manifestantes, entre eles professores de diferentes instituições, estudantes universitários e secundadriastas. Somando então, à grande mairia dos presentes, contrários as medidas adotadas pelo governo brasileiro, de fazer cortes nos recursos financeiros da educação. Conforme mostra a imgem 04, enfatizando a quantidade de pessoas com seus cartazes em mãos, em plena Av. Universitária no dia 15 de maio.

Imagem 04 - Manifestações contra cortes na educação, próximo a Pç. Universitária

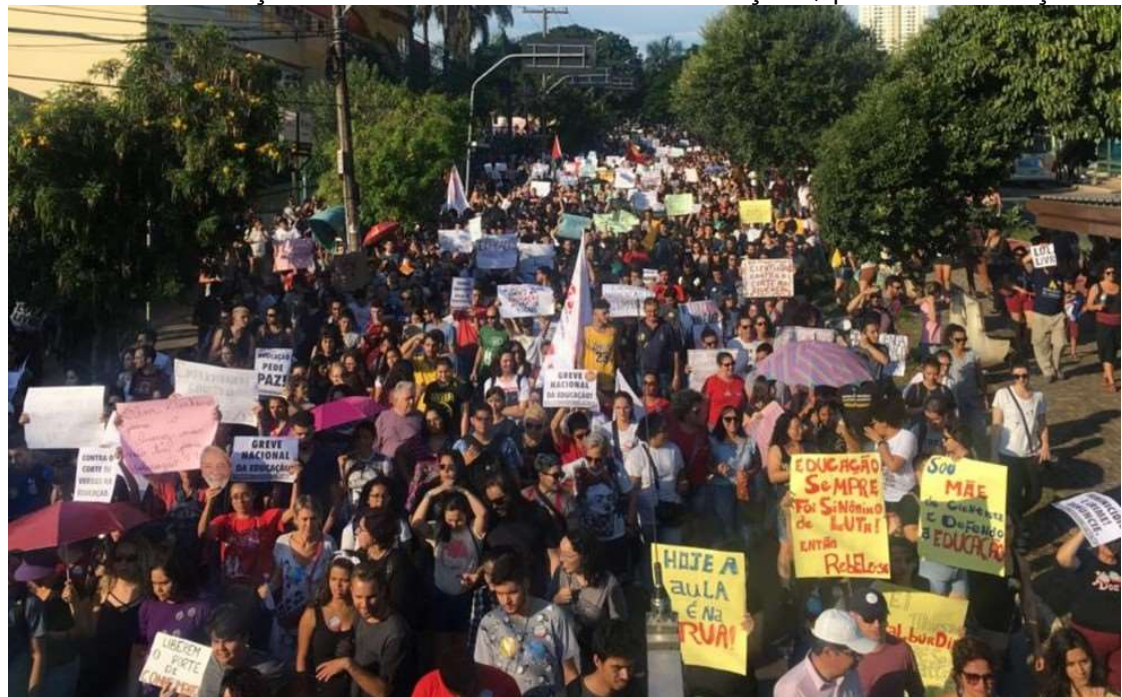

Fonte: https://gl.globo.com/go/goias/noticia/2019/05/15/goias-tem-protestos-contrabloqueios-n

Autor: Rodrigo Gonçalves 

estudantis contra os cortes na educação nas cidade de Goiânia e Londrina 15 de maio 2019.

Ao observar a imagem 04, há uma produção de sentidos que parte da relação de pertencimento, por tratar-se da cidade de Goiânia, local onde resido no momento. No entanto, existe mais do que uma relação de pertencimento envolvendo a imagem 04, pois representa um momento muito delicado, da situação política e social do país. Mesmo porque, essa situação delicada de redução e congelamento de investimentos no sistema de ensino no Brasil, é semelhante ao ocorrido no 15 de maio de 1968 em Paris.

Com isso, são vários os cartazes com mensagens de luta e contrárias aos cortes de investimento no sistema de educação, conforme anunciado pelo governo, na referida data. Contudo, frases como "hoje a aula é na rua" podem denotar o quanto os estudantes entre outros presentes na manifestação da imagem supra citada, exerceram atos de cidadania e de manifestações de forma democrática. Sendo assim, todos os participantes, aprendem na prática que manifestar-se pelos seus direitos é um dever, é ato de extrema importância para a manutenção de melhores expectativas para o país. Uma vez que uma população sem ensino de qualidade, pode estar fadada a um colapso social em um futuro próximo. No entanto, o que todas essas pessoas da imagem 04 reivindicam é o direito garantido pela constituição, que por lei destina investimentos expressivos no sistema de ensino do país.

Portanto, alunos, professores entre outras entidades que estiveram presentes nesse ato mostrado pela imagem em referencia, não estão somente pedindo algo que não lhes pertencem, mas sim exigindo o que já é garantido por lei. Com esse intuito, todos os integrantes contidos na referida imagem, descem pela Avenida Universitária, em sentido a Praça Cívica, situada no centro da cidade de Goiânia. No entanto, embora esse ângulo do recorte fogográfico não mostre, há várias viaturas da polícia acompanhando os estudantes e professores durante os protesto, que não mostram as forças policiais de repressão. Prontas para entrarem em ação, por isso "Não se olha a imagem como se olha um objeto. Olha-se segundo a imagem" (PONTY apud ALLOA, 2015 p.7). 

estudantis contra os cortes na educação nas cidade de Goiânia e Londrina 15 de maio 2019.

Domínios da imagem, v. 13, n. 25, p. 133-157, jul./dez. 2019.

Segundo a imagem, trata-se de um um ato de manifestação, conforme relata Ponty (2015), olhar "segunda a imagem" pode ser entender que as forças de repressão ausentes no recorte fotográfico, acompanham os manifestantes por todo o seu trajeto, entre algumas ruas centais da cidade de Goiania. Embora ocorrera de forma pacífica, houve todo um aparato repressor, preparado para reprimir os manifestantes, caso houvesse necessidade. Essa experiência, mostra também que "segundo a imagem" é necessário entender que as contra insurgências, poderiam ter vindo tanto pela frente, quanto pelas laterais e sobre os passeios públicos, inclusive com a cavalaria. Contudo, essas forças policiais que aparecem somente para quem passa pela vivência de atravessar o objeto explorado, faz da imagem 04 uma visualidade de movimento pacífico e democrático, como de fato foi. Porém diferente do ocorrido no 15 de maio de 1968, por esses e outros motivos é preciso "pensar a imagem" e os sentidos a elas atribuidas, e o que de fato elas podem dizer. Assim, as forças policiais estão ai de olho, prontas sempre alerta, para todo e qualquer tipo de insurgências. No entanto, não houve nesse momento, conforme a mosta a imagem a necessidade de aplicar a força do estado contra os manifestantes.

A partir do que relata Alloa (2015), é inevitável não recordar de outras imagens que compõem, outros capítulos da história recente, em que a polícia, ao reprimir estudantes durante manifestações, utilizou de ações extremamente violentas. Essas imagens de extrema violência estão dispostas na grande rede de computares, em que a netnografia pode contribuir para mostrar como e o que ocorre quando as forças de controle do estado entram em ação. Além da cavalaria, essas ações ocorrem com o uso da tropa de choque, utilizando bombas de gás lacrimogênio e também de efeito moral, como se as manifestações não atendessem também quem as coíbe. Mostrando, assim, o quanto é complexa a relação entre vida e política, sobre um conceito de labor e vida ativa [...]", descrito por (ARENDT apud RIFA-VALLS, 2019, p.8). Felizmente as manifestações ocorridas no dia 15 de maio em 
Goiânia foram pacíficas e democráticas, como mostra essa entre outras fontes visuais.

\section{Sujeito produtor de narrativas em ação exploratória no centro de Londrina.}

Esse tópico que compreendeu o segundo momento do minicurso, ocorrido durante o Eneimagem. Assim a atividade "Construindo uma narrativa sobre o espaço" teve com o tema "Arquitetura Geral", e consistia na construçao de uma atividade visual a partir de imagem, ao ar livre pela Rua Sergipe, no centro de Londrina. Desso modo, em uma ação exploratória, se deu a primeira imagem fotográfica. Pois atentos a tudo, em meio a "observação direta", confome descrevem Rocha e Eckert (2008), estavamos diante de uma arquitetura extremamente interessante. Sua significância, se dava não somente por se tratar de algo formal e esteticamente diferente de tudo que havia ao seu entorno. Mas também por se tratar de uma referência dos tempos áureos do café, ainda quando a cidade de Londrina, ou seja "a pequena Londres" se destacava por ser uma importante produtora de grãos de café.

Durante a ação exploratória, fotografando e caminhando, ao serem indagados, alguns transeuntes e comerciantes antigos da cidade, narraram que essa reconhecida produção de café, se destacou não somente pela quantidade, mas também pela qualidade dos grãos. Essa

particularidade fez com que Londrina vivesse um período de grande desenvolvimento econômico e cultural, evidenciado por edifícios como esse da imagem 05. 
NASCIMENTO, Gledson Rodrigues. Imagens fotográficas sobre autoritarismo e manifestações estudantis contra os cortes na educação nas cidade de Goiânia e Londrina 15 de maio 2019. Domínios da imagem, v. 13, n. 25, p. 133-157, jul./dez. 2019.

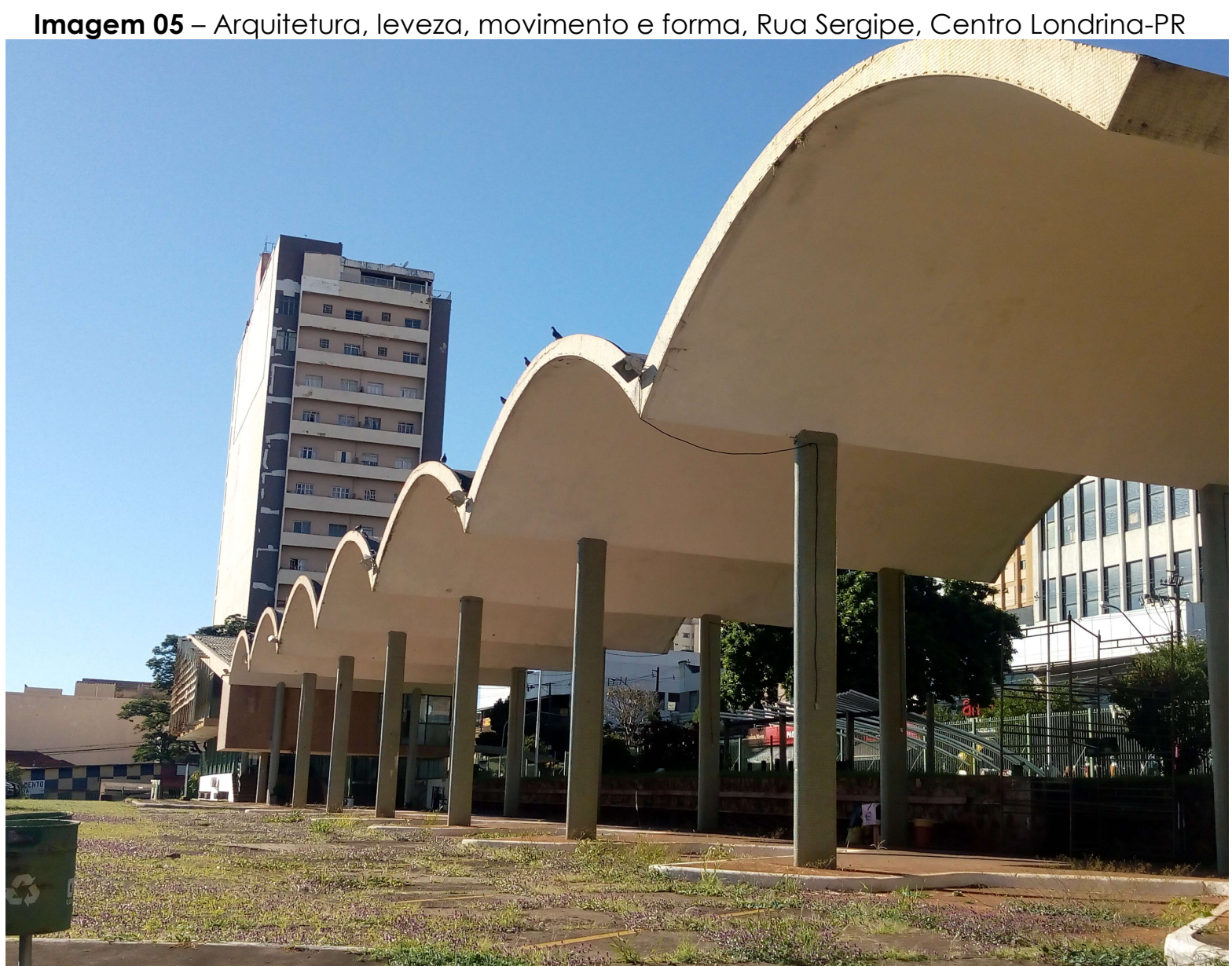

Fonte: Minicurso VII Eneimagem - UEL,

Autor: Gledson Nascimento

É sobre essa significância históriográfica que a primeira imagem fotográfica ocorre. E conforme mostra imagem 05, a arquitetura representativa que se destaca entre as demais, tratava-se da antiga rodoviária da cidade, desativada já á algum tempo, encontra-se aberta para visitas em horários específicos.

No entanto, seguimos adiante pela rua Sergipe, onde outras arquiteturas entre o azul do céu de Londrina, nos fizeram parar e realizar novas fotografias, contudo algumas dessas atravessam temáticas urbanas e sujeitos, em suas próprias narrativas cotidianas. Entre essas práticas de observar e registrar imagens, coincidentemente, nos deparamos com as manifestações do dia 15 de maio que também ocorreram no mesmo dia da atividade externa do minicurso. Assim ao dobrar a esquina da Rua Recife, nos 
NASCIMENTO, Gledson Rodrigues. Imagens fotográficas sobre autoritarismo e manifestações estudantis contra os cortes na educação nas cidade de Goiânia e Londrina 15 de maio 2019. Domínios da imagem, v. 13, n. 25, p. 133-157, jul./dez. 2019.

deparamos com um longo calçadão, nele ocorreu uma experiência antropológica visual. Pois, comerciantes e manifestantes, estavam no mesmo lugar, entre "labor e vida ativa" com o ocorrido na imagem que segue.

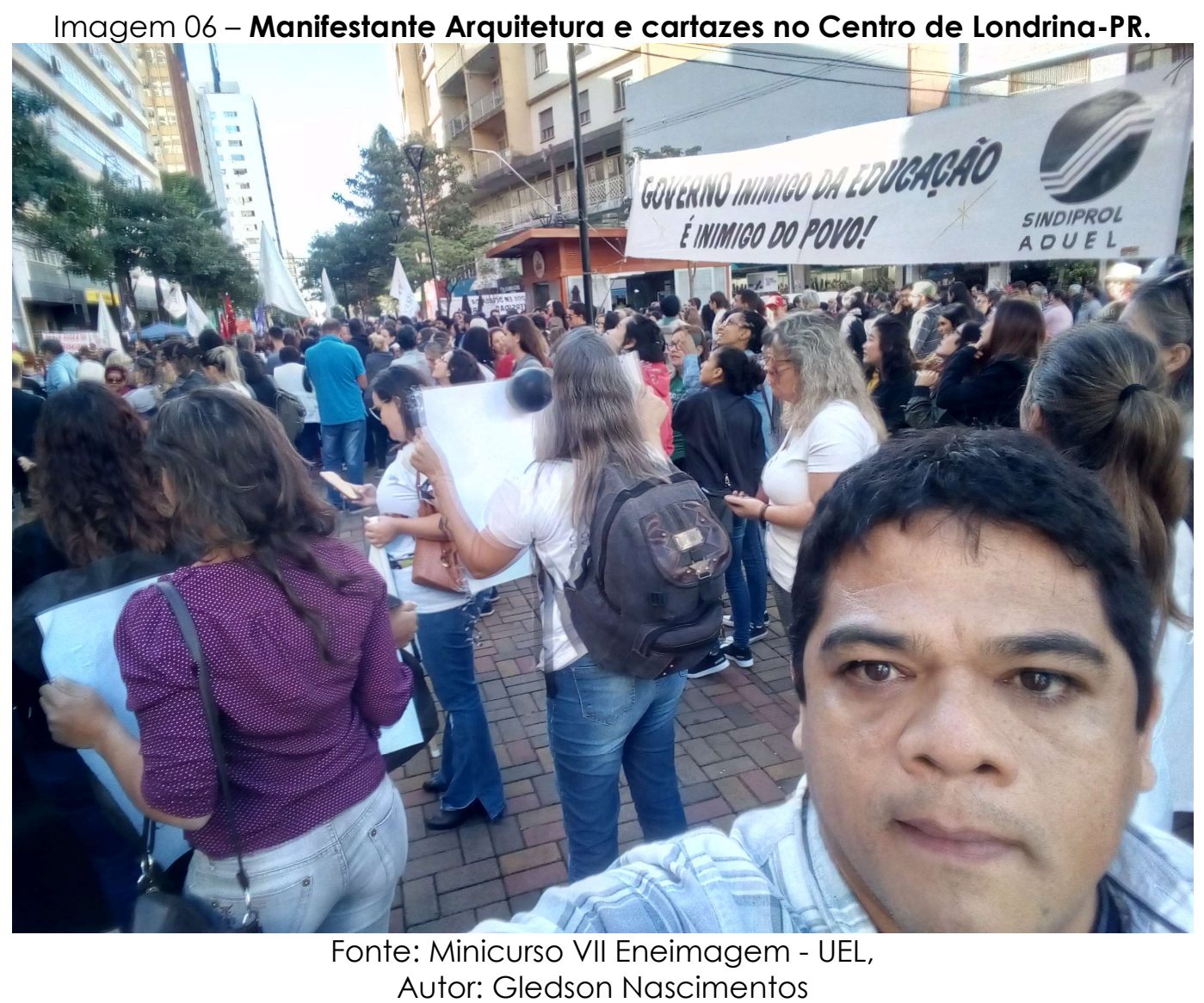

Os manifestantes que estão na imagem 06, fazem parte de um mesmo contexto, quando comparadas às fontes visuais sobre a cidade de Goiânia na mesma data. Nessa fotografia em pleno calçadão no centro de Londrina, também se concentram alunos, professores e entidades sindicais, contrários aos cortes nos recursos da educação.

E sobre um piso ladrilhado, as arquiteturas, as faixas e os cartazes compõem a narrativa visual do 15 de maio, comprovando que "A imagem tem papel virtual agregador de significados, formas, comportamentos reais do cotidiano vital." (MEIRA, 2003, P. 52). Assim como é vital, a necessidade de se manter os recursos para a educação, como também são vitais o direito e o 
NASCIMENTO, Gledson Rodrigues. Imagens fotográficas sobre autoritarismo e manifestações estudantis contra os cortes na educação nas cidade de Goiânia e Londrina 15 de maio 2019. Domínios da imagem, v. 13, n. 25, p. 133-157, jul./dez. 2019.

dever de ir para as ruas manifestar. Sejam alunos, professores, pesquisadores, trabalhadores e instituições, como o IF e a UEL, presentes com seus stands, ao mostrar o que os diferentes campos científicos desenvolvem em prol da sociedade, como ocorre na próxima imagem.

Imagem 07 - Arquiteturas e instituições no centro Londrina-PR.

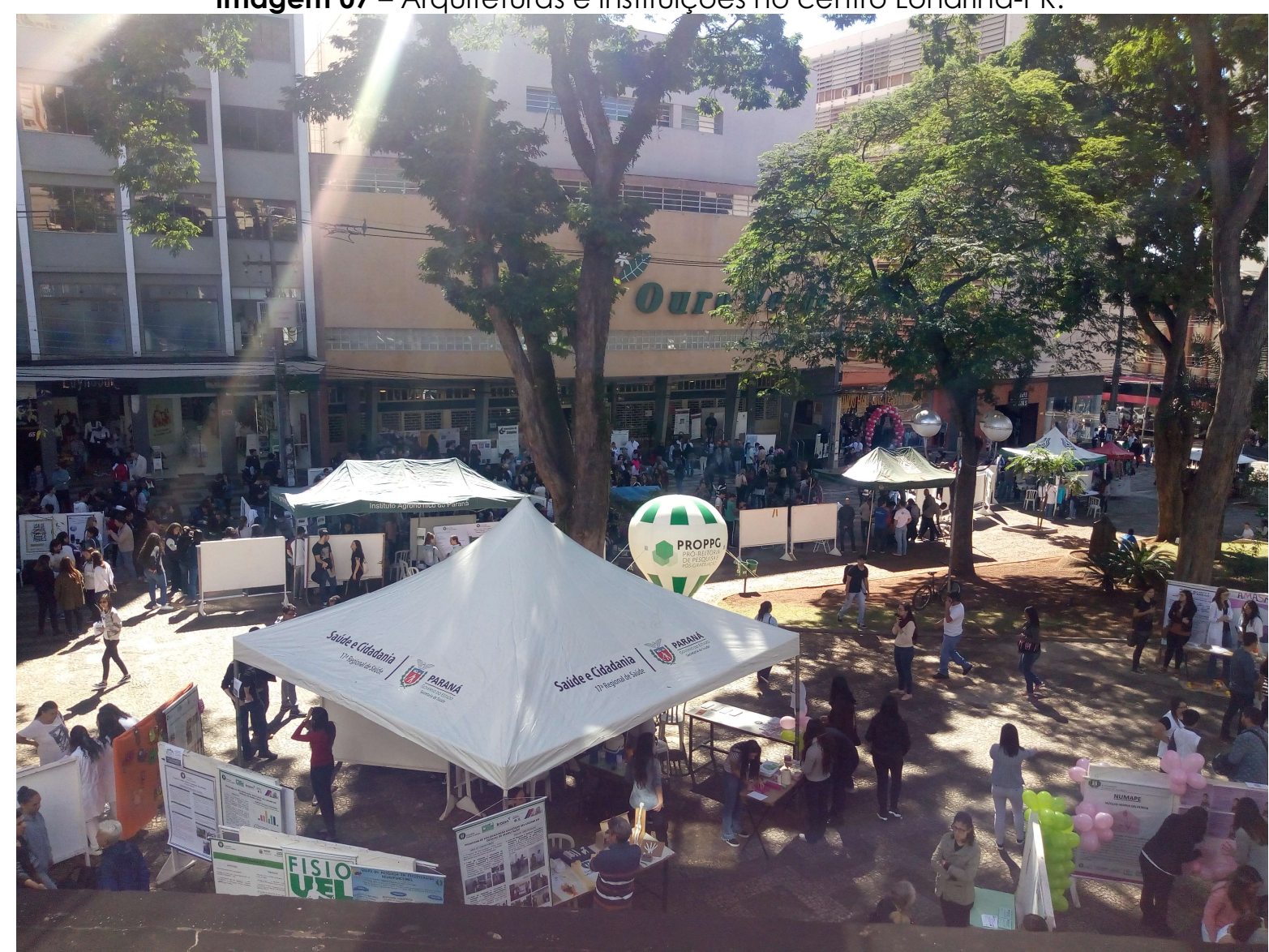

Fonte: Minicurso VII Eneimagem - UEL, Autor: Gledson Nascimentos

Essa narrativa também é construída a partir do que mostra cada uma dessas tendas em evidência na imagem 07, pois nelas encontram-se painéis, mostrando o que a universidade pública tem desenvolvido. E, além de alunos e pesquisadores de diferentes cursos, os próprios professores que estavam em algumas dessas tendas, mostravam parte do que os recursos investidos em educação, podem desenvolver para atender a sociedade. 

estudantis contra os cortes na educação nas cidade de Goiânia e Londrina 15 de maio 2019.

Domínios da imagem, v. 13, n. 25, p. 133-157, jul./dez. 2019.

Portanto, essa experiência imersiva ocorrida em Londrina, pôde gerar recortes de espaço e tempo, mostrando a quem mais possa interessar que não se trata de "balbúrdia". E sim de uma demonstração de que é necessário manter os investimentos no sistema de educação nas universidades públicas, para se desenvolver o ensino, a pesquisa e a extensão. Sobre esse contexto político, traduzido por uma imagem, Meira (1999), aponta que:

uma imagem é, também, um corpo de ideias, uma posição política sobre o contexto, um recorte ético sobre valores, um mapa de sentidos sobre algo que se aprendeu [...] os alunos captam imagens que estão ao seu redor o tempo todo, uma vez que a imagem não encontra mais barreiras para se propagar e pode-se falar de uma estética do cotidiano (MEIRA, 1999, p. 124).

Conforme descreve Meira (1999), a respeito das concepções que envolvem um mapa e um corpo de ideias sobre uma imagem, conscientemente ou não, elas detêm o poder de contextualizar o momento, os fatos, a história. Elas, também contextualizam as experiências sentidas, decorrentes das dinâmicas urbanas, entre a paisagem, recortada por imagens fotográficas. E podem ser mostradas à partir do é captado pelas câmeras de um telefone celular, de toda forma, essas mesmas dinâmicas urbanas, aglutinam pedagogias culturais em uma fotografia, que movem as ações dos sujeitos produtores de pesquisa, com e sobre imagens.

De modo, ao se produzir imagens, mesmo sobre manifestações, há a presença do sensível, entre as transcedencias contidas nas fontes visuais produzidas. E assim, espera-se que as manifestações atuais continuem, porém com a leveza transmitida pela imagem 08, considerando o que Meira (2003) classifica como "reflexões sobre o sentido do sensível". 

estudantis contra os cortes na educação nas cidade de Goiânia e Londrina 15 de maio 2019. Domínios da imagem, v. 13, n. 25, p. 133-157, jul./dez. 2019.

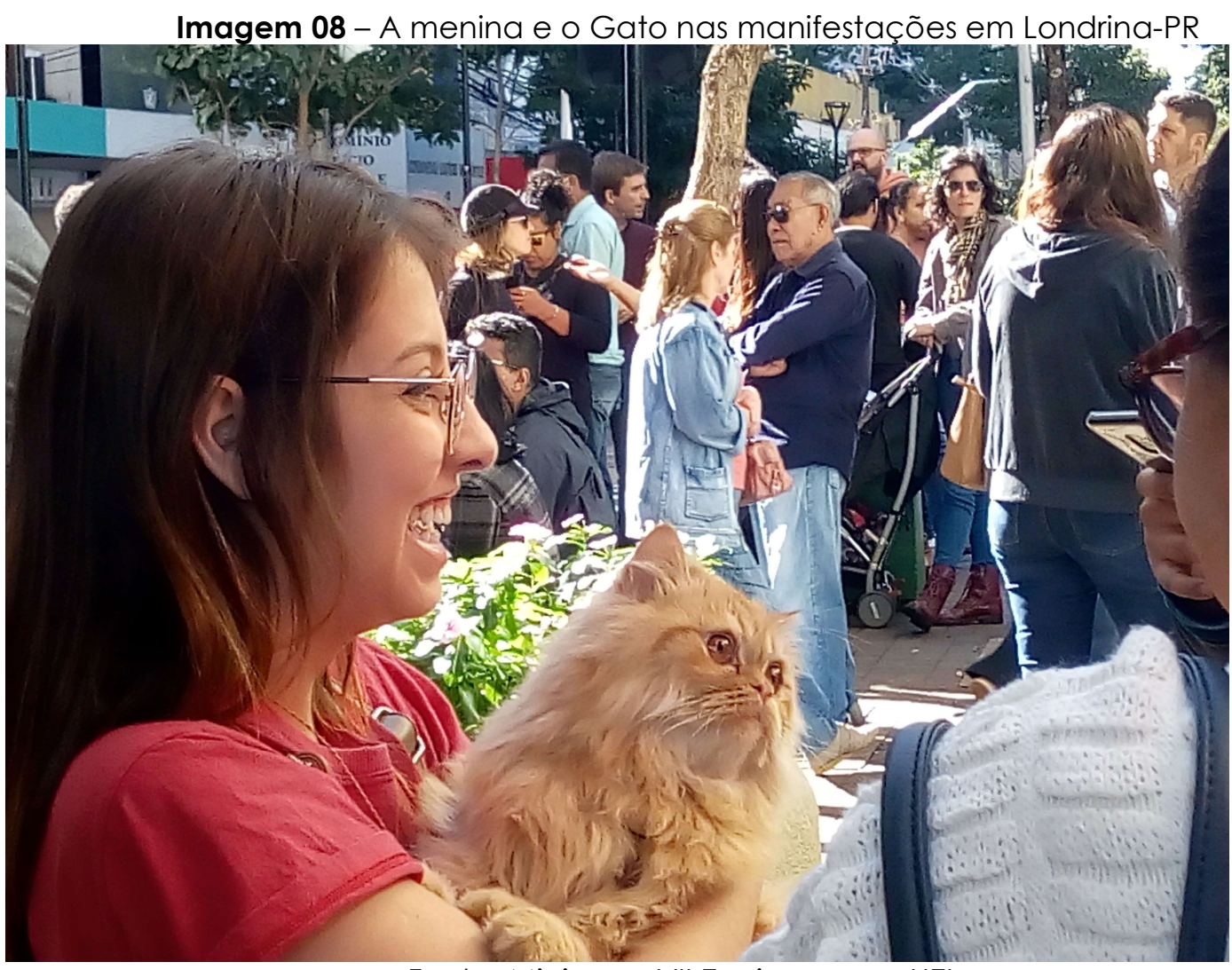

Fonte: Minicurso VII Eneimagem - UEL, Autor: Gledson Nascimento

O sentido da sensibilidade e harmonia podem ser palavras que partem de imagens produzidas por um sujeito pesquisador e produtor de imagens. Entre elas, as imagens fotograficas que foram produzidas durante as manifestações no dia 15 de maio de 2019 em Londrina e as captadas pelas redes socais, na mesma data em Goiânia.

Contudo, espera-se que outras fontes visuas, como a imagem 08 possam ser feitas novamente em manifestações, já que representaram atos pacíficos. Pois, usar a força de repressão, para calar a comunidade estudantil além de ser um ato cruel, é também desastroso para o desenvolvimento de um pais. E triste para os que se manifestam contra os desmandos e arbitrariedades do governo, como ocorreu no "maio de 68" em Paris, e também com os atos de crueldade, realizadas conra os estudantes no Brasil durante a ditadura militar. 

estudantis contra os cortes na educação nas cidade de Goiânia e Londrina 15 de maio 2019. Domínios da imagem, v. 13, n. 25, p. 133-157, jul./dez. 2019.

\section{Referências}

ALLOA, E. Entre a transparência e a opacidade - o que a imagem dá a pensar. In: ALLOA, E. (Org.) Pensar a Imagem. Belo Horizonte: Autentica Editora, 2015, p.7

CORRÊA, M. V., ROZADOS H. B. A netnografia como método de pesquisa em Ciência da Informação. Encontros Bibli: revista eletrônica de biblioteconomia e ciência da informação, v. 22, n.49, p. 1-18, maio/ago., 2017. ISSN 1518-2924. DOI: 10.5007/1518-2924.2017v22n49pl

CAMPOS. (2013). A cultura visual e o olhar antropológico - DOI 10.5216/vis.v10i1.23083. Visualidades, 10(1).

DUBOIS, P. O ato fotográfico. Campinas: Papirus, 1994.

HINE, C. Etnografia Virtual. Barcelona: Editora UOC, 2004.

HOBSBAWM, E. A era dos extremos: o breve século XX (1914 - 1991) São Paulo: Companhia das Letras, 1995.

KOZINETS, R. V. Netnografia: realizando pesquisa etnográfica online. Porto Alegre: Penso, 2014

MEIRA, M. R. Educação estética, arte e cultura do cotidiano. In: PILLAR, A. D. (Org). A educação do olhar no ensino das artes. Porto Alegre: Mediação, 1999.

MEIRA, M. R. Filosofia da Criação: reflexões sobre o sentido do sensível. Porto Alegre: Mediação, 2003.

MENESES, U. T. B. Fontes visuais, cultura visual, História visual. Balanço provisório, propostas cautelares. Revista Brasileira de História, São Paulo, v. 23, n. 45, 2003. p. 11-36.

PROTO, L. V. P. Juventude e o maio de 1968. Revista Espaço Acadêmico, v. 11, n. 129, jan. 2012. Disponível em:

http://periodicos.vem.br/ojs/index.php/EspacoAcademico/article/view/15791 Acesso em: 12 dez. 2019

RIFA-VALLS, M. Processos de fabricação visual do protesto no espaço público através de Hanna Arendt. Anais do Seminário Internacional de Pesquisa em Arte e Cultura Visual, v. 2, Set. 2018. 
ROCHA, A. L. C.; ECKERT, C. Ełnografia: Saberes e práticas. lluminuras: série de publicações eletrônicas do Banco de Imagens e Efeitos Visuais, LAS, PPGAS, IFCH e ILEA, UFRGS. Porto Alegre, N. 21 (2008), p. 23.

SANTANA, F. A. S. Atuação política do movimento estudantil no Brasil: 1964 a 1984. 2007. Dissertação (Mestrado em História) - Faculdade de Filosofia, Letras e Ciências Humanas, Universidade de São Paulo, São Paulo.

TOURAINE, A. El movimiento de Mayo el comunismo utópico. Buenos Aires: Ediciones Signos, 1970. 